\title{
Caries Diagnosis Aided by Fluorescence
}

\author{
Laurence J. Walsh \\ Additional information is available at the end of the chapter
}

http://dx.doi.org/10.5772/intechopen.75459

\begin{abstract}
Because of the limitations of visual inspection and dental radiographs for detecting early or hidden forms of dental caries, much effort has been expended developing additional methods to supplement traditional examination, Foremost amongst these has been fluorescence, which exploits the light emitting properties of bacteria deposits or of normal tooth structure. Key considerations when using fluorescence are the differences between the light emitting properties of carious versus sound tooth structure, the excitation wavelengths of light that are chosen, and the methods used to analyze fluorescence emissions. Provided that technical issues such as false positive and negative signals can be addressed, devices that employ fluorescence can improve the detection and management of dental caries, and help guide the removal of carious tooth structure during restorative procedures. Clinical recommendations for using fluorescence as an aid to caries diagnosis are based on appreciating the effects of moisture, stains, and quenching agents on readings, and altering the ambient light conditions to maximize the signal to noise ratio. Any quantitative fluorescence techniques require calibration of the device, and checks for contamination of the optics. Differences in the performance of fluorescence devices must also be considered when comparing results against thresholds for intervention.
\end{abstract}

Keywords: fluorescence, porpyhrin, QLF, DIAGNOdent, caries detection, caries removal

\section{Introduction}

The clinical diagnosis of caries is an imperfect process. As well as examining the enamel and root surfaces of teeth, clinicians must inspect the margins of restorations and sealants, and around brackets and other devices attached onto teeth that hinder plaque removal and make 
the development of caries more likely to occur. Further problems arise when the tooth surface is broken and restorative intervention is needed, since professional judgment around the extent of removal of carious tooth structure is needed.

\section{The need for adjunctive methods}

The limited performance of traditional mirror and probe examinations for dental caries is well known [1-4]. For fissure caries diagnosis, conventional approaches can easily overlook small lesions. In the primary dentition, a conventional visual-tactile technique will miss $38 \%$ of occlusal caries, including lesions of "hidden" occlusal caries that reach dentine. Such lesions are sufficiently large and demineralized enough to be detected on bitewing radiographs. These occur at a prevalence of which has a prevalence of between 4 and 15\% [5, 6]. Likewise, for primary molar proximal surface caries, a visual-tactile examination will miss $57 \%$ of carious lesions that require restorative treatment [7].

The limitations of visual methods for detecting carious lesions were highlighted in a recent analysis of 102 studies, which reported that specificity values ranged from 0.573 to 0.992 , with sensitivity values from 0.274 to 0.77 [8]. One can conclude that visual examination for dental caries is a useful method that is used widely, but it is imperfect [9].

Radiographs are also imperfect as a diagnostic approach, since small lesions are not shown. In a clinical study of 481 children aged 5-12 years attending a school-based dental clinic, only 40 out of 96 teeth that were clinically scored as showing dentine caries (42\%) had dentine radiolucencies on the bitewing radiographs [10]. Likewise, in a recent meta-analysis, for the detection of any kind of proximal lesions the sensitivity of bitewing radiographs in 24 clinical studies was $24 \%$ (CI 21-26) and the specificity was 97\% (95-98) [11]. This is why patients with high caries risk need to be examined with other more sensitive methods, rather than just relying on radiographs alone.

This chapter examines the development and deployment of adjunctive approaches to caries diagnosis using fluorescence. This approach has applications for early diagnosis, enabling pre-white spot lesions and white spot to be identified and assessed, so that remineralization of these lesions can be undertaken. Moreover, when restorative intervention is needed, fluorescence can be used to guide the removal of caries from the tooth, so that sound tooth structure is spared.

\subsection{The process of fluorescence}

Fluorescence is one of a number of processes by which materials can emit light after appropriate activation. A key feature of fluorescence is that the emission of light matches the mode of excitation, so if the light is pulsed in a particular way, the same pattern will be seen in the fluorescence emissions. When light is absorbed into a fluorophore, the molecule becomes electronically excited to higher energy levels, from where decay to lower energy levels occurs by emitting radiation and thermal relaxation. The intensity of the emission is linearly proportional to the concentration of the fluorophore present in the target, making fluorescence very useful for quantification. 
Because of the difference in energy, the color of the emitted fluorescence light is always different that of the excitation light, having a longer wavelength and a lower photon energy. Thus, violet or blue excitation light will give emissions that are green, orange or red, all of which are longer wavelengths of visible light (Table 1). Likewise, visible red excitation will give emissions in the near infrared region. This relationship is known as the Stokes' shift [12, 13].

\section{2. $405 \mathrm{~nm}$ violet light and the excitation of bacterial porphyrins}

Protoporphyrin IX and similar porphyrin molecules such as coproporphyrin are derivatives of hemoglobin, and are involved in the biosynthetic pathway for heme. Porphyrin derivatives are not present within normal healthy tooth structure, so are a useful marker for bacteria associated with dental caries. Fluorescence excitation for these fluorophores occurs strongly in the visible violet-blue range, and especially between 390 and $420 \mathrm{~nm}$, with maximum excitation at around $405 \mathrm{~nm}[14-16]$.

Violet light (405 nm wavelength) gives strong emissions from many bacterial species involved in the caries process. Lactobacilli, which are secondary colonizers of carious lesions, are stronger emitters of visible red fluorescence than are mutans streptococci. Actinomyces odontolyticus has strong porphyrin fluorescence [17]. The fluorescence characteristics of individual bacterial species vary according to the nutrients present in their environment, such as blood and associated metalloporphyrins [18]. Nevertheless, red light emissions under violet light excitation are well suited for the detection of key cariogenic bacteria [19].

Because of this feature, $405 \mathrm{~nm}$ violet light emitting diodes (LEDs) have become a preferred illumination source, and these have been used in a range of adjunctive devices for caries detection, including intra-oral cameras, stand-alone illuminators and dental high speed handpieces (Table 2).

As well as caries detection during dental examination, a further application which has emerged for such devices (discussed later in this chapter) is the use of fluorescence to guide the dental practitioner during cavity preparation in the selective removal of infected dentine.

The same caries detection devices can also be used to detect and assess mature deposits of dental plaque biofilm more than 24-h-old, as these have high levels of porphyrins and give strong red fluorescence when excited by violet light [20-22]. Higher levels of porphyrins are found in biofilms associated with bleeding gingival sites where bacteria are present that metabolize heme [23].

\begin{tabular}{lll}
\hline Target & Excitation $(\mathbf{n m})$ & Emission $(\mathbf{n m})$ \\
\hline Protoporphyrin IX & 407 & 590 \\
& & 620 \\
& & 635 \\
Mature dental plaque & $400-500$ & $600-700$ \\
& 655 & $720-800$ \\
\hline
\end{tabular}

Table 1. Typical fluorophores of interest in caries diagnosis. 


\begin{tabular}{lll}
\hline Intra-oral camera & Penscope $^{\mathrm{TM}}$ & Morita Corp., Kyoto, Japan \\
\hline PenViewer $^{\mathrm{TM}}$ & Morita Corp., Kyoto, Japan \\
G-Cam ${ }^{\mathrm{TM}}$ & GC Corp., Tokyo, Japan \\
& VistaCam ${ }^{\circledR}$ & Durr Dental, Bietigheim-Bissingen, Germany \\
& VistaCam ix Proof ${ }^{\mathrm{TM}}$ & Durr Dental, Bietigheim-Bissingen, Germany \\
Cam X Spectra & Air Techniques, Melville NY, USA \\
SiroInspect & Sirona, Bensheim, Germany \\
Qlluminator & QLF-D Biluminator 2 + TM & Inspektor Research Systems, \\
& Amsterdam, The Netherlands \\
Fental handpiece & Lares Research, Chico, CA, USA. \\
\hline
\end{tabular}

Table 2. Caries detection systems using $405 \mathrm{~nm}$ violet light.

When using $405 \mathrm{~nm}$ violet light in the clinical setting, drying tooth surfaces or, conversely, the presence of saliva over a tooth surface, do not affect the red fluorescence emissions from bacterial porphyrins in carious lesions or from dental plaque [24]. However, fluorescence readings are altered when visible traces of blood appear in the saliva because the patient has gingivitis. This confounding factor needs to be considered when examining teeth in areas where gingivitis is present.

\subsection{QLF and the assessment of enamel mineral loss}

Quantitative light-induced fluorescence (QLF) is based on the principle that as a tooth develops dental caries, the green fluorescence of normal enamel that is emitted under illumination with short wavelength (violet-blue) light reduces, making white spot lesions that are below the normal diagnostic threshold become visible.

Healthy teeth with no enamel lesions fluoresce green in a consistent even manner. This feature of human teeth has been known for more than 100 years. The organic (protein) components of tooth structure are responsible for this, and certain fluorophores such as the amino acid tryptophan account for the normal fluorescence of sound dentine when exposed to violet or ultraviolet light. As caries develops in enamel there is marked reduction in green fluorescence, mostly because of changes in light scattering properties as the mineral content reduces and the water content in the enamel rises. This phenomenon was observed at the Karolinska Institute in Sweden in the late 1970's and was characterized using laser light as the excitation source in the early 1980s [25-27].

When caries develops in the enamel, less of the incident violet-blue light reaches the dentinoenamel junction, which is where a high concentration of fluorophores is present that emit green light. Using this approach, fluorescence photographic or video (frame grabber) images of enamel surfaces that have white spot lesions can be digitized, and the difference between these areas and adjacent normal enamel on the same tooth (i.e., fluorescence loss) quantified 
[28]. The extent of fluorescence loss correlates strongly with mineral loss within the enamel as assessed using transverse microradiography and other methods, making QLF a sensitive and valid method for quantifying mineral loss in carious lesions in the enamel [29, 30].

A significant decrease in the intensity of the green fluorescence signal occurs in both demineralized sites and in areas where there is caries in the dentine [27, 31, 32]. A reduction in green fluorescence from the enamel is also seen in conditions where the composition of the enamel is altered, such as in fluorosis or when interruptions to tooth formation occur during tooth development. In the case of dental fluorosis or enamel formation defects, the shape and location of these areas are quite different from those of dental caries [33].

QLF has been used in both laboratory and clinical studies to assess mineral loss and mineral gain in various caries models and in high caries risk patients, respectively. The method shows good agreement with other fluorescence-based approaches [34-36]. In terms of benefits for clinicians, QLF can detect about twice as many demineralized pre-cavitated enamel areas (pre-white spot lesions and white spot lesions) as a conventional visual examination [37]. In addition to enamel on smooth surfaces, QLF can also be used to examine interdental areas. Care must be taken to optimize the angulation at which the teeth are viewed $[38,39]$.

QLF has been undertaken using the argon ion laser (wavelength $488 \mathrm{~nm}$ ) and blue diode lasers (wavelength $470 \mathrm{~nm}$ ), however most devices used for QLF have employed a lamp with blueviolet emissions as the light source (e.g., Inspektor ${ }^{\mathrm{TM}}$ Pro, Inspektor Research Systems BV, Amsterdam, The Netherlands). The more recent version of this technology uses an array of LEDs (QLF-D Biluminator 2+, Inspektor Research Systems). In these systems, a camera collects fluorescence emissions that have been filtered through a high-pass filter (wavelengths $>520 \mathrm{~nm}$ ). Image analysis is undertaken on a personal computer using purpose-designed software, such as Inspektor C4 QLF Research Suite. For calculating fluorescence loss, the fluorescence of sound enamel at the lesion site is reconstructed from the fluorescence of sound enamel bordering the lesion. The error of using this reconstruction approach has been shown to be very small (mean difference $1.6 \%$ ), over areas up to $14 \mathrm{~mm}^{2}$ [29].

\section{4. $655 \mathrm{~nm}$ red light excitation and the DIAGNOdent}

The DIAGNOdent (Kavo, Biberach, Germany) uses pulsed visible red light (wavelength $655 \mathrm{~nm}$ ) to elicit fluorescence from bacteria and their products, in the near infrared range. The device provides readings of fluorescence intensity on a scale of 0-100 [40]. The DIAGNOdent Classic detects porphyrin derivatives with a detection limit in the order of 1 picomole [41]. While many Gram negative bacteria are strongly fluorescent, the DIAGNOdent can also detect planktonic species as well as biofilms of mutans streptococci [42].

DIAGNOdent technology exists in three physical forms: the DIAGNOdent Classic, the DIAGNOdent Pen, and the KEY-3 laser. In the latter, the fluorescence system is integrated into an Er:YAG treatment system and used to selectively fire the treatment laser as a type of guidance or autopilot system.

The emitted fluorescence light, for example from lesions deep in fissures or at the dentinoenamel junction, is detected readily because enamel has high transparency in the near infrared 
region [43]. This makes the DIAGNOdent useful for detecting lesions in dentine that are not visible on clinical examination but may be seen on radiographs (if these were taken). Thus, when bitewing radiographs are not be taken, the diagnosis of occult dentinal caries may be further enhanced by using the DIAGNOdent at recall examinations [44].

A major application of the DIAGNOdent is screening occlusal surfaces for caries that has reached the restorative threshold of the dentino-enamel junction. This method works well in both primary and permanent teeth [45-47]. Applications of the DIAGNOdent extend beyond the detection of fissure caries to include the monitoring of non-cavitated incipient lesions, both in the enamel and on the root surface [48]. In such clinical applications, it is important to remember that the various DIAGNOdent systems assess the presence of bacteria, and not the level of mineral in the tooth structure per se [49].

Because of the high reproducibility of DIAGNOdent readings and consistency between devices of the same type produced over successive years, one properly calibrated DIAGNOdent device may be replaced by a new one without introducing errors [50].

The DIAGNOdent can be used to examine smooth surfaces of teeth. Validation of the DIAGNOdent Classic unit for quantification of lesions, comparing the results to histopathological and microradiographic analyses as a gold standard, had produced non-linear (rank order) correlation coefficients between lesion depth and DIAGNOdent readings of between 0.78 and 0.85 , with very high inter- and intra-examiner agreement (0.94 and 0.95) [51]. Likewise, high levels of performance for detection of smooth surface caries have also been shown for the DIAGNOdent Pen, which gives similar (but not identical) readings [52, 53].

\subsubsection{DIAGNOdent assessment of white spot lesions}

In white spot lesions, bacterial products such as porphyrins become trapped in areas of porosity on the surface. When all overlying dental plaque biofilm is removed by professional cleaning, the retained bacterial products can still be detected. When DIAGNOdent readings trend upwards over time, this is closely associated with white spot lesions that eventually break down to form a cavity. Conversely, stable DIAGNOdent scores over prolonged periods of time are associated with stability and are a feature of arrested white spot lesions [54].

\subsubsection{Performance of the DIAGNOdent}

An important issue when using a DIAGNOdent is applying the appropriate cut-off levels to distinguish between sound and carious tooth structure, since this will influence the decision of the clinical operator to follow a remineralization approach, or to intervene restoratively. A number of threshold values have been stated in the literature, which take into account the normal background readings of sound tooth structure. A DIAGNOdent reading of five or less is typical for normal healthy enamel and dentine.

A recent systematic review of the performance of DIAGNOdent in laboratory settings included 39 studies. The pooled sensitivity was 0.71 (CI $0.69-0.73$ ), and the specificity was $0.81(0.73,0.82)$. For the receiver operating characteristic curve, the area under the curve was 0.865 , signifying strong performance. The conclusion from this meta-analysis was that laser 
fluorescence had the ability to diagnose occlusal caries lesions in permanent teeth and enamel and dentine caries [55].

Overall, when the DIAGNOdent Classic is used for caries detection, it gives a superior sensitivity over traditional methods, since small hidden lesions can be detected. The challenge in using the device comes from the fact that specificity values can be lower, particularly when the problems of false positive readings are not addressed [56]. Plaque that remains in a fissure will give a positive reading for fluorescence, and will compromise correct diagnosis of caries at that site [57]. Likewise, if extrinsic stains are present on teeth (e.g., from red wine), DIAGNOdent scores will rise on both the stained surfaces of enamel and on stained surfaces of restorations. The latter could lead to false-positive diagnoses of secondary caries. For this reason, restoration margins should be polished prior to DIAGNOdent measurements being taken [58].

Care should be taken when selecting a polishing paste, since some pastes can have fluorescence properties and thereby interfere with taking accurate DIAGNOdent readings [59]. This can be checked for easily by testing samples of the polishing material dispensed onto a mixing pad on the bench with the DIAGNOdent.

Assessment of the possibility of dental caries underneath sealants with DIAGNOdent is influenced by the filler content, opacity and intrinsic fluorescence of the sealant. Clear sealants will attenuate DIAGNOdent readings less than opaque sealants. Likewise, filled sealants attenuate readings more than unfilled sealants. The presence of titanium dioxide (added in to make the material have a white color) can cause intrinsic fluorescence, and also interfere with transmission of fluorescence emissions through the sealant. For these reasons, the use of DIAGNOdent to assess caries under dental sealants is not reliable as readings are likely to be inaccurate [60].

Clinical recommendations for using the DIAGNOdent are summarized in Table 3 . This also includes general points that apply to all caries detection devices based on fluorescence.

\subsubsection{DIAGNOdent pen}

Following the release of the DIAGNOdent Classic in 1998-1999, the Pen version followed in 2005. It is much smaller size and better battery life was due to a change in the digital display from LEDs to a liquid crystal display. As with the Classic, the DiagnoDENT pen gives a variable pitch acoustic tone, and records both the more important "peak" fluorescence score as well as the momentary score.

The DIAGNOdent Pen can take a range of different tips. A conical tip is used for assessing fissures, and this is used in the same manner as the " $\mathrm{A}$ " tip of the DIAGNOdent Classic. A tip designed for the assessment of approximal enamel surfaces has a bevel that directs and collects the light at an angle of 100 degrees, which effectively functions like a periscope, allowing the approximal enamel surface of one posterior tooth to be assessed. The periscope tip has a marking to show which direction it is facing (mesial or distal). If a cavitation is present, not only will bacterial products be present in the tooth structure, they will also be present in high concentrations in the dental plaque biofilm inside the cavity. This gives a strong fluorescence emission and a high reading, which helps the clinician an answer to the important question of whether the surface is cavitated or not. 
Remove all stains and dental plaque from the teeth, using a non-fluorescing cleaning agent

Remove excess moisture, but do not over-dry the teeth. Traces of saliva are acceptable, but there must not be any blood present over the surface.

Be aware of extraneous bright light sources such as direct sunlight that may affect the teeth. For some devices, turn off the operatory light to improve contrast.

Be aware of endogenous fluorescence of restorative materials, and variations in fluorescence with teeth in the one dentition

Teeth with discoloration from first and second generation tetracycline antibiotics will have elevated background fluorescence

Hold the tip against the surface

Keep the optical components (windows, tips, etc.) free of all contamination

* Correctly calibrate the fluorescence system as per the manufacturer's instructions

* If making fluorescence measurements, do not do this immediately after the application of oxidizers or other quenching agents

* Take measurements at least twice and record the maximum value

* Do not attempt to quantify fluorescence under sealants

*= requirements for quantitative systems, e.g., DIAGNOdent.

Table 3. Clinical recommendations for using fluorescence as an aid to caries diagnosis.

The diagnostic accuracy of the DIAGNOdent Pen for detecting approximal caries lesions, in posterior primary teeth and permanent teeth, at the cavitation and non-cavitation thresholds, is superior to digital bitewing radiography $[61,62]$. In a recent study, the optimal fluorescence cut-off values with the DIAGNOdent Pen for detecting approximal caries lesions were 8 for non-cavitated lesions, and $>16$ for cavitated lesions. For cavitated lesions on approximal surfaces, the reported performance values were $100 \%$ for sensitivity, $85 \%$ for specificity and $95 \%$ for accuracy (based on the area under the receiver-operating characteristic curve). For non-cavitated (white spot) lesions, these metrics were 92, 90 and 95\%, respectively [63].

Both the DIAGNOdent Classic and Pen systems use the same basic design, and one would expect that their performance (once they are properly calibrated) would be identical. In fact, variations in performance occur between them, with the Pen being more sensitive [64-66].

\subsubsection{DIAGNOdent and assessing the extent of caries removal}

Studies using extracted teeth with frank cavitations and stepwise caries removal using a range of methods have shown that DIAGNOdent values reduce during caries removal, as the infected dentine is taken away. Typical end values are 5-6 at the cavity floor, and 9 at the dentino-enamel junction. An appropriate threshold to use for caries removal is a DIAGNOdent score of 7 for circumpulpal dentine. Removal of caries to this point, if done using an Er:YAG laser, corresponds to the point where dentine collagen cross-links are intact, which signifies vital dentine [67]. 
When using fluorescence to guide Er:YAG laser caries removal, a confounding factor to avoid is deposits of beta tricalcium phosphate which can form when there is inadequate water mist spray or when the laser tip is pushed against the enamel surface during lasing. These deposits, which occur as a result of high temperature effects within enamel [68], give strong near infrared fluorescence emissions when excited by visible red light, and thus are a false positive signal that could be mistaken for infected carious dentine [69].

A final factor of importance for real time DIAGNOdent measurements of cavity preparations or tooth surfaces is quenching of fluorescence, which causes much lower readings and thus a false negative result. Applications of hydrogen peroxide and ozone can cause an immediate reduction in readings, and recovery from this takes up to $24 \mathrm{~h}$ [70].

\section{5. $450 \mathrm{~nm}$ blue light for fluorescence diagnosis}

In the SoproLife ${ }^{\circledR}$ intra-oral camera (Sopro-Acteon group, La Ciotat, France), visible blue light with a wavelength of $450 \mathrm{~nm}$ is used to excite fluorescence. Image processing enhances the green fluorescence of healthy tooth structure and the red fluorescence of dental caries.

A clinical study reported that, when using ICDAS as a reference standard, the performance of the Soprolife in terms of sensitivity and specificity for occlusal caries detection (43\%) was less than that of the DIAGNOdent (62\%) [71]. In a recent systematic review of the detection of occlusal caries, reported values for sensitivity for the Soporlife ranged between $43 \%$ and $95 \%$, and for specificity between 55 and $100 \%$ [72]. Due to a limited number of clinical studies, further work is needed to confirm the validity of the SoproLife ${ }^{\circledR}$ intra-oral camera for detecting occlusal carious lesions.

\subsection{Fluorescence-assisted caries excavation}

The use of fluorescence to detect carious dentine remaining after cavity preparation is a technique known as fluorescence-assisted caries excavation (FACE). Teeth are illuminated with violet-blue light, and then examined using a filter which blocks the reflected excitation light, but allows longer wavelengths to pass. A $530 \mathrm{~nm}$ high-pass filter allows yellow, orange and red fluorescence emissions to pass. Carious dentine will fluoresce in the orange-red region. This approach is superior to conventional visual tactile (mirror and probe) examination of the cavity, and also to staining using basic fuchsin dye or acid red dye, with higher sensitivity and better specificity [73]. Caries detecting dyes do not stain bacteria in infected dentine, but rather collagen within areas where the organic matrix is altered, which means that they can also stain areas of healthy tooth structure [74-76].

To undertake FACE, the area of interest in the cavity is illuminated with $405 \mathrm{~nm}$ violet light, and then viewed using an orange-colored high-pass filter. The clinician can then use their instrument of choice to remove selectively all orange-red fluorescing areas. By following the FACE method, the caries excavation time is reduced, with fewer bacteria remaining in the floor of the cavity, when compared to conventional excavation, or chemo-mechanical caries removal $[77,78]$. These benefits apply equally well in primary as in permanent teeth [79]. 


\subsection{Clinical implications}

Many studies have concluded that the use of fluorescence can improve the detection of carious lesions, particularly at an early stage. DIAGNOdent assessment is very useful for detection of secondary lesions, and results are highly reproducible between different examiners [80,81]. This is an important clinical point since secondary caries is the major reason for failure of restorations. Better assessment lowers the possibility of over-diagnosis, and unnecessary repeated restoration replacement.

Because hidden deep lesions are a major challenge for traditional visual examination, it is in this area that fluorescence methods are very useful. Unlike radiographic examination, fluorescence examination is non-hazardous, and can be repeated as often as needed. In line with this conclusion, a 2013 meta-analysis of 75 studies of fluorescence-based methods for detecting caries lesions reported a trend of better performance of fluorescence methods over conventional methods for detecting more advanced carious lesions [82].

Clinical guidelines in most countries advise dentists and dental therapists who are treating children to not rely on visual examination alone, but to take radiographs to detect lesions on approximal surfaces and on occlusal surfaces that would be missed by visual inspection. In this context, fluorescence methods are an adjunct to and not a replacement for conventional methods of examination. Using fluorescence methods as adjuncts will improve sensitivity, as well as reproducibility between different clinicians [83, 84].

This then leads to discussion of what would be an appropriate or ideal sequence for clinical examination for dental caries in a manner which integrates fluorescence as an adjunctive method. Prior to the full examination, dental plaque can be shown to the patient, for the purposes of oral hygiene instruction. At this point, mature deposits of plaque can be shown using fluorescence. Calculus deposits will also fluoresce.

The next step is to remove plaque and stains, so that tooth surfaces can be examined properly. This includes flossing to remove plaque from interdental spaces.

At this point, traditional charting is undertaken using good lighting and magnification. Results from the primary visual inspection should use ICMS (ICDAS-II) or a similar system to record white spot lesions. Drying the teeth well can make these lesions more apparent, and can make pre-white spot lesions appear. Any probes used should be blunt, and only used to remove traces of debris that remain in the depths of fissures.

The next step is to use a violet-blue light fluorescence device to examine the teeth, such as an illuminator, camera, intra-oral camera or specialized dental handpiece. This examination will reveal a number of interesting features, including the true size of white spot and pre-white spot lesions because of their reduced green fluorescence. If $405 \mathrm{~nm}$ violet light is used, the presence of various tooth-colored restorations and fissure sealants may also become much more apparent because these do not perfectly replicate the fluorescence of natural tooth structure [85].

All restorations can now be charted. The extent of bacterial presence on incipient root lesions or open cavitated coronal lesions can be gauged by the extent of red fluorescence under violet light [86]. 
The next step is to use a DIAGNOdent Pen to examine pits and fissures using a conical sapphire tip. The conical tip is then replaced with the beveled tip, and an examination of the approximal enamel surfaces undertaken. A decision is then made regarding the need to use any additional special tests, such as fiber optic transillumination or bitewing radiographs, if cavitations are detected on these surfaces.

Unlike dental X-rays, fluorescence uses non-ionizing radiation and thus there are no concerns with its repeated use when it is used to monitor surfaces. The ability to better detect caries at an early stage makes it easier for the dental practitioner to apply effective remineralizing treatments to incipient enamel or root surface carious lesions, to cause caries arrest and reversal $[87,88]$.

\subsection{Taking fluorescence diagnostic applications forward}

While there are many fluorescence already in use in clinical dental practice, the technology continues to develop further. Some notable expansions of fluorescence diagnosis applications for dental caries include:

- The use of dyes to aid in detection and quantification of early demineralization $[89,90]$

- The use of fluorescence ratio reference standards (FRRS) to discriminate different stages of dental caries [91].

- The use of multispectral fluorescence imaging, to distinguish between dental caries, dental calculus and fluorescence from restorative materials [92].

- The use of micro-Raman spectroscopy to provide objective evaluation of different zones within carious dentine, for minimally invasive operative caries management [93].

- The use of systems that simultaneously measure backscattering of light as well as fluorescence emissions [94].

Such technical improvements will add to the ability of dental clinicians to recognize both caries and restorations, and promote the practice of minimal intervention dentistry.

\section{Conclusion}

Fluorescence methods can enhance the detection and clinical management of dental caries, as an adjunct to traditional methods. Because fluorescence employs low power visible light, it can be used with safety at every dental appointment, to assess and monitor lesions. It is essential that clinicians using fluorescence methods understand the factors that affect fluorescence, and particularly the problems of false positive and false negative signals, so that appropriate measures can be put in place to address these. Correct sequencing of fluorescence inspection in the overall flow of clinical examination will remove common factors such as dental plaque that can interfere with fluorescence assessment of tooth structure. Fluorescence methods used during caries excavation can provide a useful endpoint and prevent excessive removal of tooth structure. 


\section{Acknowledgements}

I thank the many graduate students who have worked with me in fluorescence studies in dentistry over the past 30 years, and particularly Fardad Shakibaie, Roy George, Caron Tran, Jovena Chan, Suhayla Mubarak, Andrew McQuillan, Andrew Sainsbury and Quan Ho.

\section{Conflict of interest}

The author jointly holds patents on specialized optical fibers for fluorescence diagnosis, and on couplings for dental handpieces and cameras for fluorescence diagnosis in clinical dental practice. No other conflicts of interest are declared.

\section{Author details}

Laurence J. Walsh

Address all correspondence to: 1.walsh@uq.edu.au

The University of Queensland School of Dentistry, Brisbane, Australia

\section{References}

[1] Angmar-Mansson B, ten Bosch JJ. Advances in methods for diagnosing coronal cariesA review. Advances in Dental Research. 1993;7(2):70-79

[2] Bader J, Shugars DA, Bonito AJ. Systematic review of selected dental caries diagnosis and management methods. In: NIH Consensus Development Conference on Diagnosis and Management of Dental Caries Throughout Life. Journal of Dental Education. Bethesda, MD; March 26-28, 2001;65(10):960-969

[3] Bader JD, Shugars DA, Bonito AJ. A systematic review of the performance of methods for identifying carious lesions. Journal of Public Health Dentistry. 2002;62(4):201-213

[4] Braga MM, Mendes FM, Ekstrand KR. Detection activity assessment and diagnosis of dental caries lesions. Dental Clinics of North America. 2010;54(3):479-493. DOI: 10.1016/j. cden.2010.03.006

[5] Weerheijm KL, Gruythuysen RJ, van Amerongen WE. Prevalence of hidden caries. ASDC Journal of Dentistry for Children. 1992;59(6):408-412

[6] Ricketts D, Kidd E, Weerheijm K, de Soet H. Hidden caries: What is it? Does it exist? Does it matter? International Dental Journal. 1997;47(5):259-265 
[7] Newman B, Seow WK, Kazoullis S, Ford D, Holcombe T. Clinical detection of caries in the primary dentition with and without bitewing radiography. Australian Dental Journal. 2009;54(1):23-30. DOI: 10.1111/j.1834-7819.2008.01084.x

[8] Gimenez T, Piovesan C, Braga MM, Raggio DP, Deery C, Ricketts DN, Ekstrand KR, Mendes FM. Visual inspection for caries detection: A systematic review and meta-analysis. Journal of Dental Research. 2015;94(7):895-904. DOI: 10.1177/0022034515586763

[9] Hoskin ER, Keenan AV. Can we trust visual methods alone for detecting caries in teeth? Evidence-Based Dentistry. 2016;17(2):41-42. DOI: 10.1038/sj.ebd.6401165

[10] Fracaro MS, Seow WK, McAllan LH, Purdie DM. The sensitivity and specificity of clinical assessment compared with bitewing radiography for detection of occlusal dentin caries. Pediatric Dentistry. 2001;23(3):204-210

[11] Keenan JR, Keenan AV. Accuracy of dental radiographs for caries detection. EvidenceBased Dentistry. 2016;17(2):43. DOI: 10.1038/sj.ebd.6401166

[12] Shakibaie F, George R, Walsh LJ. Applications of laser-induced fluorescence in dentistry. International Journal of Dental Clinics. 2011;3(2):26029

[13] Walsh LJ, Shakibaie F. Ultraviolet-induced fluorescence: Shedding new light on dental biofilms and dental caries. Australasian Dental Practice. 2007;18(6):56-60

[14] König K, Flemming G, Hibst R. Laser-induced autofluorescence spectroscopy of dental caries. Cellular and Molecular Biology (Noisy-le-Grand, France). 1998;44(8):1293-1300

[15] Buchalla W, Lennon AM, Attin T. Comparative fluorescence spectroscopy of root caries lesions. European Journal of Oral Sciences. 2004;112(6):490-496

[16] Buchalla W. Comparative fluorescence spectroscopy shows differences in non-cavitated enamel lesions. Caries Research. 2005;39(2):150-156

[17] Koenig K, Schneckenburger H. Laser-induced autofluorescence for medical diagnosis. Journal of Fluorescence. 1994;4(1):17-40. DOI: 10.1007/BF01876650

[18] Volgenant CM, van der Veen MH, de Soet JJ, ten Cate JM. Effect of metalloporphyrins on red autofluorescence from oral bacteria. European Journal of Oral Sciences. 2013;121 (3 Pt 1):156-161. DOI: 10.1111/eos.12045

[19] Lennon AM, Buchalla W, Brune L, Zimmermann O, Gross U, Attin T. The ability of selected oral microorganisms to emit red fluorescence. Caries Research. 2006;40(1):2-5. DOI: $10.1159 / 000088898$

[20] Coulthwaite L, Pretty IA, Smith PW, Higham SM, Verran J. The microbiological origin of fluorescence observed in plaque on dentures during QLF analysis. Caries Research. 2006;40(2):112-116. DOI: 10.1159/000091056

[21] van der Veena MH, Volgenanta CMC, Keijsera B, ten Cate JM, Crielaard W. Dynamics of red fluorescent dental plaque during experimental gingivitis-A cohort study. Journal of Dentistry. 2016;48:71-76 
[22] Han SY, Kim BR, Ko HK, Kwon HK, Kim BI. Assessing the use of quantitative light-induced fluorescence-digital as a clinical plaque assessment. Photodiagnosis and Photodynamic Therapy. 2016;13:34-39

[23] Slots J, Reynolds HS, Long-wave UV. Light fluorescence for identification of black-pigmented Bacteroides spp. Journal of Clinical Microbiology. 1982;16(6):1148-1151

[24] Shakibaie F, Walsh LJ. Effect of oral fluids on dental caries detection by the VistaCam. Clinical and Experimental Dental Research. 2015;1(2):74-79. DOI: 10.1002/cre2.13

[25] Bjelkhagen H, Sundström F. A clinically applicable laser luminescence method for the early detection of dental caries. IEEE Journal of Quantum Electronics. 1981;17(12):266-270. DOI: 10.1109/JQE.1981.1071024

[26] Bjelkhagen H, Sundström F, Angmar-Månsson B, Rydén H. Early detection of enamel caries by the luminescence excited by visible laser light. Swedish Dental Journal. 1982; 6(1):1-7

[27] Sundström F, Fredriksson K, Montan S, Hafstrom-Bjorkman U, Strom J. Laser-induced fluorescence from sound and carious tooth substance: Spectroscopic studies. Swedish Dental Journal. 1985;9(2):71-80

[28] van der Veen MH, de Josselin de Jong E. Application of quantitative light-induced fluorescence for assessing early caries lesions. Monographs in Oral Science. 2000;17:144-162

[29] de Josselin de Jong E, Sundström F, Westerling H, Tranaeus S, ten Bosch JJ, AngmarMånsson B. A new method for in vivo quantification of changes in initial enamel caries with laser fluorescence. Caries Research. 1995;29(1):2-7

[30] Emami Z, Al-Khateeb S, de Josselin de Jong E, Sundström F, Trollsås K, Angmar-Månsson B. Mineral loss in incipient caries lesions quantified with laser fluorescence and longitudinal microradiography. A methodologic study. Acta Odontologica Scandinavica. 1996;54(1):8-13

[31] Ando M, van Der Veen MH, Schemehorn BR, Stookey GK. Comparative study to quantify demineralized enamel in deciduous and permanent teeth using laser- and lightinduced fluorescence techniques. Caries Research. 2001;35(6):464-470

[32] Nakata K, Nikaido T, Ikeda M, Foxton RM, Tagami J. Relationship between fluorescence loss of QLF and depth of demineralization in an enamel erosion model. Dental Materials Journal. 2009;28(5):523-529

[33] Angmar-Månsson B, de Josselin de Jong E, Sundström F, ten Bosch JJ. Strategies for improving the assessment of dental fluorosis: Focus on optical techniques. Advances in Dental Research. 1994;8(1):75-79

[34] Hafstrom-Bjorkman U, Sundström F, Angmar-Månsson B. Initial caries diagnosis in rat molars, using laser fluorescence. Acta Odontologica Scandinavica. 1991;49(1):27-33 
[35] Hafstrom-Bjorkman U, Sundström F, deJosselin deJong E, Oliveby A, Angmar-Månsson B. Comparison of laser fluorescence and longitudinal microradiography for quantitative assessment of in vitro enamel caries. Caries Research. 1992;26(4):241-247

[36] Aljehani A, Tranaeus S, Forsberg CM, Angmar-Månsson B, Shi XQ. In vitro quantification of white spot enamel lesions adjacent to fixed orthodontic appliances using quantitative light-induced fluorescence and DIAGNOdent. Acta Odontologica Scandinavica. 2004;62(6):313-318. DOI: 10.1080/00016350410001793

[37] Stookey GK. Quantitative light fluorescence: A technology for early monitoring of the caries process. Dental Clinics of North America. 2005;49(4):753-770

[38] Buchalla W, Lennon AM, van der Veen MH, Stookey GK. Optimal camera and illumination angulations for detection of interproximal caries using quantitative light-induced fluorescence. Caries Research. 2002;36(5):320-326

[39] Ko HY, Kang SM, Kim HE, Kwon HK, Kim BI. Validation of quantitative light-induced fluorescence-digital (QLF-D) for the detection of approximal caries in vitro. Journal of Dentistry. 2015;43:568-575

[40] Hibst R, Paulus R, Lussi A. Detection of occlusal caries by laser fluorescence: Basic and clinical investigations. Medical Laser Application. 2001;16(3):205-213

[41] Lussi A, Hibst R, Paulus R. DIAGNOdent: An optical method for caries detection. Journal of Dental Research. 2004;83(Spec No C):C80-C83

[42] Sainsbury AL, Bird PS, Walsh LJ. DIAGNOdent laser fluorescence assessment of endodontic infection. Journal of Endodontia. 2009;35(10):1404-1407

[43] Fried D, Featherstone JD, Darling CL, Jones RS, Ngaotheppitak P, Bühler CM. Early caries imaging and monitoring with near-infrared light. Dental Clinics of North America. 2005;49(4):771-793

[44] Chong MJ, Seow WK, Purdie DM, Cheng E, Wan V. Visual-tactile examination compared with conventional radiography, digital radiography, and Diagnodent in the diagnosis of occlusal occult caries in extracted premolars. Pediatric Dentistry. 2003;25(4):341-349

[45] Costa AM, Yamaguti PM, De Paula LM, Bezerra AC. In vitro study of laser diode $655 \mathrm{~nm}$ diagnosis of occlusal caries. ASDC Journal of Dentistry for Children. 2002;69(3):249-253, 233

[46] Costa AM, Paula LM, Bezerra AC. Use of DIAGNOdent for diagnosis of non-cavitated occlusal dentin caries. Journal of Applied Oral Science. 2008;16(1):18-23

[47] Kucukyilmaz E, Sener Y, Botsali MS. In vivo and in vitro performance of conventional methods, DIAGNOdent, and an electronic caries monitor for occlusal caries detection in primary teeth. Pediatric Dentistry. 2015;37(4):E14-E22

[48] Vlacic J, Meyers IA, Walsh LJ. Combined CPP-ACP and photoactivated disinfection (PAD) therapy in arresting root surface caries: A case report. British Dental Journal. 2007;203(8): 457-459 
[49] Astvaldsdóttir A, Tranæus S, Karlsson L, Peter Holbrook W. DIAGNOdent measurements of cultures of selected oral bacteria and demineralized enamel. Acta Odontologica Scandinavica. 2010;68(3):148-153. DOI: 10.3109/00016350903567176

[50] Alwas-Danowska HM, Plasschaert AJ, Suliborski S, Verdonschot EH. Reliability and validity issues of laser fluorescence measurements in occlusal caries diagnosis. Journal of Dentistry. 2002;30(4):129-134

[51] Shi XQ, Tranaeus S, Angmar-Månsson B. Validation of DIAGNOdent for quantification of smooth-surface caries: An in vitro study. Acta Odontologica Scandinavica. 2001;59(2):74-78

[52] Aljehani A, Yang L, Shi XQ. In vitro quantification of smooth surface caries with DIAGNOdent and the DIAGNOdent pen. Acta Odontologica Scandinavica. 2007;65(1): 60-63. DOI: 10.1080/00016350601058051

[53] Nokhbatolfoghahaie H, Alikhasi M, Chiniforush N, Khoei F, Safavi N, Yaghoub Zadeh B. Evaluation of accuracy of DIAGNOdent in diagnosis of primary and secondary caries in comparison to conventional methods. Journal of Lasers in Medical Sciences. 2013;4(4): 159-167

[54] Walsh LJ, Clifford H. Changes in Diagnodent scores in smooth surface enamel carious lesions in primary teeth: A longitudinal clinical study. Journal of Oral Laser Applications. 2008;8(3):157-164

[55] Rosa MI, Schambeck VS, Dondossola ER, Alexandre MC, Tuon L, Grande AJ, Hugo F. Laser fluorescence of caries detection in permanent teeth in vitro: A systematic review and metaanalysis. Journal of Evidence-Based Medicine. 2016;9(4):213-224. DOI: 10.1111/jebm.12227

[56] Bader JD, Shugars DA. A systematic review of the performance of a laser fluorescence device for detecting caries. Journal of the American Dental Association (1939). 2004; 135(10):1413-1426

[57] Tomczyk J, Komarnitki J, Zalewska M, Lekszycki T, Olczak-Kowalczyk D. Fluorescence methods (VistaCam iX proof and DIAGNODent pen) for the detection of occlusal carious lesions in teeth recovered from archaeological context. American Journal of Physical Anthropology. 2014;154(4):525-534. DOI: 10.1002/ajpa.22542

[58] Hitij T, Fidler A. Effect of dental material fluorescence on DIAGNOdent readings. Acta Odontologica Scandinavica. 2008;66(1):13-17. DOI: 10.1080/00016350701810641

[59] Hosoya Y, Matsuzaka K, Inoue T, Marshall GW. Influence of tooth-polishing pastes and sealants on DIAGNOdent values. Quintessence International. 2004;35(8):605-611

[60] Gostanian HV, Shey Z, Kasinathan C, Caceda J, Janal MN. An in vitro evaluation of the effect of sealant characteristics on laser fluorescence for caries detection. Pediatric Dentistry. 2006;28(5):445-450

[61] de Souza JF, Diniz MB, Boldieri T, Rodrigues JA, Lussi A, de Cássia Loiola Cordeiro R. In vitro performance of a pen-type laser fluorescence device and bitewing radiographs for approximal caries detection in permanent and primary teeth. Indian Journal of Dental Research. 2014;25(6):702-710. DOI: 10.4103/0970-9290.152165 
[62] RibeiroAA, Purger F, RodriguesJA, Oliveira PR, Lussi A, MonteiroAH, Alves HD, AssisJT, Vasconcellos $\mathrm{AB}$. Influence of contact points on the performance of caries detection methods in approximal surfaces of primary molars: An in vivo study. Caries Research. 2015;49(2):99-108. DOI: 10.1159/000368562

[63] Menem R, Barngkgei I, Beiruti N, Al Haffar I, Joury E. The diagnostic accuracy of a laser fluorescence device and digital radiography in detecting approximal caries lesions in posterior permanent teeth: An in vivo study. Lasers in Medical Science. 2017;32(3): 621-628. DOI: 10.1007/s10103-017-2157-2

[64] Matos R, Novaes TF, Braga MM, Siqueira WL, Duarte DA, Mendes FM. Clinical performance of two fluorescence-based methods in detecting occlusal caries lesions in primary teeth. Caries Research. 2011;45(3):294-302. DOI: 10.1159/000328673

[65] Diniz MB, Boldieri T, Rodrigues JA, Santos-Pinto L, Lussi A, Cordeiro RC. The performance of conventional and fluorescence-based methods for occlusal caries detection: An in vivo study with histologic validation. Journal of the American Dental Association (1939). 2012;143(4):339-350

[66] Shakibaie F, Walsh LJ. Performance differences in the detection of subgingival calculus by laser fluorescence devices. Lasers in Medical Science. 2015;30(9):2281-2286. DOI: 10.1007/s10103-015-1808-4

[67] Eberhard J, Eisenbeiss AK, Braun A, Hedderich J, Jepsen S. Evaluation of selective caries removal by a fluorescence feedback-controlled Er:YAG laser in vitro. Caries Research. 2005;39(6):496-504

[68] Aminzadeh A, Shahabi S, Walsh LJ. Raman spectroscopic studies of $\mathrm{CO}_{2}$ laser-irradiated human dental enamel. Spectrochimica Acta. 19991;55:1303-1308

[69] Walsh LJ. The current status of laser applications in dentistry. Australian Dental Journal. 2003;48(3):146-155

[70] Walsh LJ, Mubarak S, McQuillan A. Autopilot laser-based systems for guiding caries and calculus removal: From concept to clinical reality. Australasian Dental Practice. 2007;18(5):122-128

[71] Theocharopoulou A, Lagerweij MD, van Strijp AJ. Use of the ICDAS system and two fluorescence-based intraoral devices for examination of occlusal surfaces. European Journal of Paediatric Dentistry. 2015;16(1):51-55

[72] Doméjean S, Rongier J, Muller-Bolla M. Detection of occlusal carious lesion using the SoproLife ${ }^{\circledR}$ camera: A systematic review. The Journal of Contemporary Dental Practice. 2016;17(9):774-779

[73] Lennon AM, Buchalla W, Switalski L, Stookey GK. Residual caries detection using visible fluorescence. Caries Research. 2002;36(5):315-319

[74] Anderson MH, Loesche WJ, Charbeneau GT. Bacteriologic study of a basic fuschin caries disclosing dye. The Journal of Prosthetic Dentistry. 1985;54:51-55 
[75] Kidd EA, Joyston-Bechal S, Beighton D. The use of a caries detector dye during cavity preparation: A microbiological assessment. British Dental Journal. 1993;174:245-248

[76] Zacharia MA, Munshi AK. Microbiological assessment of dentin stained with a caries detector dye. The Journal of Clinical Pediatric Dentistry. 1995;19:111-115

[77] Lennon AM, Buchalla W, Rassner B, Becker K, Attin T. Efficiency of 4 caries excavation methods compared. Operative Dentistry. 2006;31(5):551-555. DOI: 10.2341/05-92

[78] Lennon AM, Attin T, Buchalla W. Quantity of remaining bacteria and cavity size after excavation with FACE, caries detector dye and conventional excavation in vitro. Operative Dentistry. 2007;32(3):236-241. DOI: 10.2341/06-64

[79] Lennon AM, Attin T, Martens S, Buchalla W. Fluorescence-aided caries excavation (FACE), caries detector, and conventional caries excavation in primary teeth. Pediatric Dentistry. 2009;31(4):316-319

[80] Rodrigues JA, Neuhaus KW, Hug I, Stich H, Seemann R, Lussi A. In vitro detection of secondary caries associated with composite restorations on approximal surfaces using laser fluorescence. Operative Dentistry. 2010;35(5):564-571. DOI: 10.2341/09-332-L

[81] Brouwer F, Askar H, Paris S, Schwendicke F. Detecting secondary caries lesions: A systematic review and meta-analysis. Journal of Dental Research. 2016;95(2):143-151. DOI: $10.1177 / 0022034515611041$

[82] Gimenez T, Braga MM, Raggio DP, Deery C, Ricketts DN, Mendes FM. Fluorescencebased methods for detecting caries lesions: Systematic review, meta-analysis and sources of heterogeneity. PLoS One. 2013;8(4, 4):e60421. DOI: 10.1371/journal.pone.0060421

[83] Neuhaus KW, Rodrigues JA, Hug I, Stich H, Lussi A. Performance of laser fluorescence devices, visual and radiographic examination for the detection of occlusal caries in primary molars. Clinical Oral Investigations. 2011;15(5):635-641. DOI: 10.1007/s00784010-0427-5

[84] Mendes FM, Novaes TF, Matos R, Bittar DG, Piovesan C, Gimenez T, Imparato JC, Raggio DP, Braga MM. Radiographic and laser fluorescence methods have no benefits for detecting caries in primary teeth. Caries Research. 2012;46(6):536-543. DOI: 10.1159/000341189

[85] Kiran R, Walsh LJ, Forrest A, Tennant M, Chapman J. Forensic applications: Fluorescence properties of tooth-coloured restorative materials using a fluorescence DSLR camera. Forensic Science International. 2017;273:20-28. DOI: 10.1016/j.forsciint.2017.01.022

[86] Shakibaie F, Walsh LJ. Violet and blue light-induced green fluorescence emissions from dental caries. Australian Dental Journal. 2016;61(4):464-468. DOI: 10.1111/adj.12414

[87] Walsh LJ. Topical CPP-ACP crèmes: Beyond caries prevention. International Dental Journal. 2014;9(4):48-58

[88] Walsh LJ. Molecular and pharmaceutical aspects of novel methods and materials for the prevention of tooth structure loss. Current Pharmaceutical Biotechnology. 2017;18(1): 45-51. DOI: 10.2174/1389201017666161207163851 
[89] Mendes FM, de Oliveira E, de Faria DL, Nicolau J. Ability of laser fluorescence device associated with fluorescent dyes in detecting and quantifying early smooth surface caries lesions. Journal of Biomedical Optics. 2006;11(2):024007. DOI: 10.1117/1.2191046

[90] Alencar CJ, Braga MM, de Oliveira E, Nicolau J, Mendes FM. Dye-enhanced laser fluorescence detection of caries lesions around brackets. Lasers in Medical Science. 2009;24(6):865-870. DOI: 10.1007/s10103-008-0572-0

[91] Thomas SS, Mohanty S, Jayanthi JL, Varughese JM, Balan A, Subhash N. Clinical trial for detection of dental caries using laser-induced fluorescence ratio reference standard. Journal of Biomedical Optics. 2010;15(2):027001. DOI: 10.1117/1.3365945

[92] Singh SP, Fält P, Barman I, Koistinen A, Dasari RR, Kullaa AM. Objective identification of dental abnormalities with multispectral fluorescence imaging. Journal of Biophotonics. 2017;10(10):1279-1286. DOI: 10.1002/jbio.201600218

[93] Almahdy A, Downey FC, Sauro S, Cook RJ, Sherriff M, Richards D, Watson TF, Banerjee A, Festy F. Microbiochemical analysis of carious dentine using Raman and fluorescence spectroscopy. Caries Research. 2012;46(5):432-440. DOI: 10.1159/000339487

[94] Kesler G, Masychev V, Sokolovsky A, Alexandrov M, Kesler A, Koren R. Photon undulatory non-linear conversion diagnostic method for caries detection: A pilot study. Journal of Clinical Laser Medicine \& Surgery. 2003;21(4):209-217. DOI: 10.1089/104454703768247783 
